\title{
Use of Ligasure Sealing Versus Conventional Suture - Ligation in Total Thyroidectomy
}

\author{
Wael AlJuraibi ${ }^{1}$, Mohamed Rifaat Ahmed ${ }^{2}$, Aly Saber ${ }^{3}$ \\ ${ }^{1}$ Department of otolaryngology \& Head and neck surgery, Al Hayat National hospital, Jazan, Saudi Arabia \\ ${ }^{2}$ Department of Otolaryngology, faculty of medicine, Suez Canal University,Ismailia, Egypt \\ ${ }^{3}$ Port-Fouad general Hospital, Port-Fouad, Egypt
}

\section{Email address}

drwael39@yahoo.com (W. A. Juraibi),drwael39@gmail.com (W. A. Juraibi),m_rifaat@hotmail.com (M. R. Ahmed), Alysaber54@gmail.com (A. Saber)

\section{To cite this article:}

Wael Al Juraibi, Mohamed Rifaat Ahmed, Aly Saber. Use of Ligasure Sealing Versus Conventional Suture - Ligation in Total Thyroidectomy. Journal of Surgery. Special Issue: Surgical Infections and Sepsis. Vol. 4, No. 3-1, 2016, pp. 34-38. doi: 10.11648/j.js.s.2016040301.17

Received: April 8, 2016; Accepted: April 10, 2016; Published: June 4, 2016

\begin{abstract}
Introduction: Effective vessel haemostasis can be achieved by suture knot tying technique or newer techniques of vessel haemostasis like ligasure as an alternative bipolar surgical diathermy system. Various diathermy techniques have been proposed to reduce intraoperative blood loss in surgery and the new electrothermal bipolar tissue sealing system (Ligasure) has been applied in various specialties of surgery. The objective of this randomized study was to compare the outcome of ligasure versus conventional clamping and tie in total thyroidectomy for benign thyroid diseases. Patients and Methods: A total of 200 patients diagnosed to have bilateral BMNG were subjected to primary total thyroidectomy and divided into two main groups Ligasure (L) and Suture-Ligation (SL). For detection of laryngeal nerves status, vocal cords were checked immediately postoperatively by laryngoscope and at the day 10 of postoperative period to assess the status of both laryngeal nerves. The function of the parathyroids was checked by detecting the serum calcium concentration and parathyroid hormone level. The following parameters were measured to compare the effect of ligasure versus conventional suture-ligation technique in decreasing the operative blood loss, operative time, securing laryngeal nerves and parathyroids, postoperative drainage and postoperative wound infection. Results: There was no statistical difference between the two groups regarding age, sex and body mass index and also there was no operative mortality. As regard the operative time, in ligasure group it was $115.54 \pm 15.35$ minutes while in suture-ligation group was 127.1 \pm 7.95 minutes and intraoperative blood loss in group A was $62.06 \pm 7.34$ and in group B was 75.84 9.21. Temporary RLN injury was detected in 3 patients (3\%) in group A and in 5 patients in group B (5\%). No permanent hypoparathyroidism was seen in group A patients but in one patient (1\%) of group B, transient hypoparathyroidism occurred in 2 patients $(2 \%)$ of both groups. The amount of fluid drained in group A was 54.16 \pm 9.21 and $66.28 \pm 8.99$ in group B. Conclusion: The use of the Ligasure sealing system in total thyroidectomy is proved safe and effective in reducing the operative time, intraoperative blood loss together with reduction in postoperative fluid drainage. Owing to the ability to reduce energy spread profile, use of Ligasure sealing system is accompanied with better outcome regarding the function of laryngeal nerves and parathyroids.
\end{abstract}

Keywords: Ligasure, Suture-Ligation, Total Thyroidectomy, Outcome

\section{Introduction}

Various diathermy techniques have been proposed to reduce intraoperative blood loss in surgery and the new electrothermal bipolar tissue sealing system (Ligasure) has been applied in various specialties of surgery [1-3]. The Ligasure instruments utilize a high current, low-voltage bipolar radiofrequency energy, in combination with a feedback-controlled response system that automatically delivers and disrupts the power according to the composition and impedance of the tissue between the jaws of the instrument [4].

Total thyroidectomy has been accepted as current surgical therapy for benign and malignant thyroidal disorders but 
extensive resection might increase the risk of postoperative complications [5]. During thyroidectomy bleeding may obscure the operative field making safe dissection of recurrent laryngeal nerve and parathyroid gland difficult and prolonging the operation time. Thyroid surgery involves meticulous devascularization of the thyroid gland, which has one of the richest blood supplies of all organs, with numerous blood vessels and plexuses entering its parenchyma. Therefore, hemostasis is of paramount importance when dividing the various vessels before excising the gland [6]. Effective vessel haemostasis can be achieved by suture knot tying technique or newer techniques of vessel haemostasis like ligasure as an alternative bipolar surgical diathermy system [7]. Postoperative bleeding complications and hematoma formation are observed slightly more in case of total than subtotal thyroidectomy due to the extensive resection performed $[5,8]$. The objective of this randomized study was to compare the outcome of ligasure versus conventional clamping and tie in total thyroidectomy for benign thyroid diseases.

\section{Patients and Methods}

A total of 200 patients diagnosed to have bilateral BMNG were enrolled to this prospective analytic study conducted in Port Fouad General Hospital, Port-Fouad, Egypt from April 2008 to December 2014. Patients were subjected to primary total thyroidectomy due to compression symptoms and/ or huge neck swelling without previous neck surgery or radiotherapy. All patients data were collected such as demographic data (age at diagnosis, gender, occupation and residence), and presenting symptoms (dysphagia dyspnea, hoarseness, and others). Our patients were divided into two main groups Ligasure (L) and Suture-Ligation (SL). Written consent was obtained from all patients or first-degree relatives before the management procedure and the local ethics committee approved the study.

\subsection{Randomization}

Randomization was performed prior to study commencement as follows: opaque envelopes were numbered sequentially from 1 to 200 . A computer-generated table of random numbers was used for group assignment; if the last digit of the random number was from 0 to 4 , assignment was to group A ( L group), and if the last digit was from 5 to 9, assignment was to group B (SL group). The assignments were then placed into the opaque envelopes and the envelopes sealed. As eligible participants were entered into the trial, these envelopes were opened in sequential order to give each patient his or her random group assignment. The envelopes were opened by the operating surgeon after patient consent and just prior to the surgery

\subsection{Preoperative Workup}

The status of vocal cords for all patients was checked in the preoperative period our otorhinolarygologist using direct rigid laryngoscope (rigid laryngeal endoscope, Storz $70^{\circ}$ with video monitor was used for laryngeal evaluation) during maximum phonation and maximum inspiration (full adduction and full abduction) to ensure intact both superior laryngeal nerve (SLN) and RLN. The preoperative preparation for thyroidectomy for the BMNG patients included the following investigations: neck ultrasound, determination of free $\mathrm{T} 3$, free $\mathrm{T} 4$, thyroid stimulating hormone and serum calcium concentration, and fine-needle aspiration cytology.

\subsection{Postoperative Period}

For detection of laryngeal nerves status, vocal cords were checked immediately postoperatively by laryngoscope and at the day 10 of postoperative period to assess the status of both laryngeal nerves. Temporary RLN paralysis after 6 months was considered permanent. Clinical evidence of SLN injury was considered as breathy voice or diminished vocal frequency range, especially with regard to raising pitch. Using direct laryngoscope, signs of bowing, and inferior displacement of the affected cord on examination were diagnostic [5]. The function of the parathyroids was checked immediately in the postoperative period by detecting the serum calcium concentration and parathyroid hormone level. Postoperative hypocalcaemia was considered when calcium level was lower than $8.0 \mathrm{mg} / \mathrm{dL}$ (reference range $8.2-10.2$ $\mathrm{mg} / \mathrm{dL}$ ). Temporary hypocalcemia was defined as a calcium level lower than $8.0 \mathrm{mg} / \mathrm{dL}$ in at least two consecutive samples (twice daily for 3 days). In these patients, hypocalcemia resolved within days. Conversely, in patients who were symptomatic and required vitamin $\mathrm{D}$ with or without calcium supplementation, we considered temporary hypocalcemia to be severe when calcium levels remained lower than $8.0 \mathrm{mg} / \mathrm{dL}$ for more than 3 days. In these patients, hypocalcemia resolved within 6 months. In patients who required vitamin $\mathrm{D}$ and calcium supplementation for more than 6 months, we considered hypoparathyroidism to be permanent [5].

\subsection{Outcome Parameters}

The following parameters were measured to compare the effect of ligasure versus conventional suture-ligation technique in decreasing the operative blood loss, operative time, securing laryngeal nerves and parathyroids, postoperative drainage and postoperative wound infection.

\subsection{Statistical Analysis}

Data collected were processed using SPSS version 15 (SPSS Inc., Chicago, IL, USA). Quantitative data were expressed as means \pm SD while qualitative data were expressed as numbers and percentages (\%).

\section{Results}

There was no statistical difference between the two groups regarding age, sex and body mass index and also there was 
no operative mortality in our patients as shown in table 1. The mean age was $42.25 \pm 9.5$ years in patients of group $\mathrm{A}$ and was $40.19 \pm 9.6$ years in patients of group B with insignificant distribution.

Table 1. Showing patients distribution regarding sex.

\begin{tabular}{llll}
\hline Group & Male & Female & Total \\
\hline A & 41 & 59 & 100 \\
B & 39 & 61 & 100 \\
total & 80 & 120 & 200 \\
\hline
\end{tabular}

As regard the operative time, in ligasure group it was between 90-120 minutes with a mean value of $115.54 \pm 15.35$ minutes while in suture-ligation group, the operative time was between 110-140 minutes with a mean value of $127.1 \pm 7.95$ minutes and this difference is considered to be extremely statistically significant $[\mathrm{t}=5.0148$, df $=198, \mathrm{P} \leq$ $0.0001]$.

The amount of intraoperative blood loss using the standard absorptive gauze measuring $30 \mathrm{~cm}$ X $30 \mathrm{~cm}$ was $50-75 \mathrm{ml}$ in group $\mathrm{A}($ mean $62.06 \pm 7.34$ ) and $60-90$ in group B ( mean $75.84 \pm 9.21)$ respectively and this difference is considered to be extremely statistically significant $[\mathrm{t}=11.7007, \mathrm{df}=198, \mathrm{P}$ $\leq 0.0001]$ as shown in figure 1 .

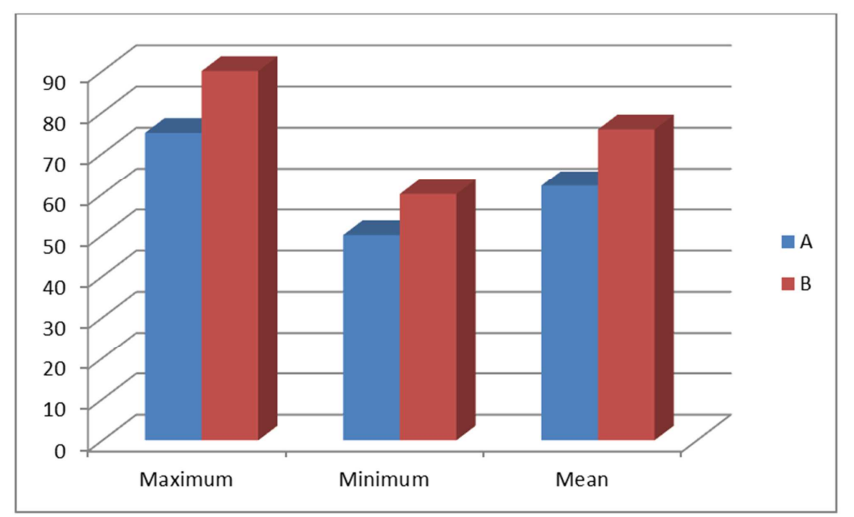

Figure 1. Showing the maximum, minimum and mean amounts of intraoperative blood loss.

No permanent or bilateral recurrent laryngeal nerve injuries occurred for patients in both groups. Temporary RLN injury was detected in 3 patients ( $3 \%$ ) in group $A$ and in 5 patients in group B $(5 \%)$. No permanent hypoparathyroidism was seen in group A patients but in one patient (1\%) of group $\mathrm{B}$, transient hypoparathyroidism occurred in 2 patients $(2 \%)$ of both groups.

The amount of fluid drained in group A was 40-70 ml $\{54.16 \pm 9.21\}$ and $50-80 \mathrm{ml}\{66.28 \pm 8.99\}$ respectively and this difference is considered to be extremely statistically significant $[\mathrm{t}=9.4170, \mathrm{df}=198, \mathrm{P} \leq 0.0001]$.

\section{Discussion}

An accurate dissection and hemostasis is essential in order to provide a clear surgical field during total thyroidectomy, minimize the risk of structural damage, prevent post-surgical hemorrhage and avoid the need for surgical drains; however, the safest, most efficient and cost-effective way to achieve these goals is still under debate [9]. In the present study, we used the ligasure sealing system in order to achieve proper intraoperative haemostasis and allow good field visualization. The use of Ligasure sealing system at the experimental level [4] and in clinical studies [10] allows the surgeon to improve vessel sealing with minimal thermal spread to the surrounding tissue and these instruments can seal vessels of up to and including $7 \mathrm{~mm}$ in diameter $[4,8,10]$.

Regarding the operative time, our data came in concordance with those reported in previous studied and the authors of these studies found significant difference in operative time reduction in case of ligasure $[6,11,12,13]$. The conventional suture knot tying technique requires a large number of surgical ties and this maneuver is time consuming and requires good exposure [7]

Estimation of intra-operative blood loss is governed by visual method [14] and the clinical assessment with collaboration with the anesthetist [15]. Regarding visual estimation of blood loss; the authors in this present study relied on the standard absorptive gauze measuring $30 \mathrm{~cm} \mathrm{X}$ $30 \mathrm{~cm}$. When it was soaked by $50 \%$ the means that it contains about $25 \mathrm{ml}$ of blood and if totally soaked; $100 \%$ this means that it contains $75 \mathrm{ml}$ of blood [16]. Many researchers reported significant reduction of intra-operative blood loss by the use of ligasure system in total thyroidectomy when compared with the conventional sutureligation technique $[6,17,18,19]$ and our data came in agreement with those reported results. The ligasure vessel sealing system can apply control, sealing vessels up to $7 \mathrm{~mm}$ in diameter and facilitates surgery by achieving the efficient haemostasis of blood vessels encountered during dissection, and allowing the rapid and secure division of vascularised tissues, while minimizing thermal injury to adjacent tissues [20]. Ligasure created less thermal damage to the media of the vessels [4] and utilizes both electrical and elastin in vessel walls and tissue to provide haemostasis [8].

In total thyroidectomy using the conventional sutureligation technique, the overall laryngeal nerve injury was reported in our previous studies to be around 5.8\% and transient hypoparathyroidism occurred in $3.3 \%[5,21,22]$. Laryngeal nerve dysfunction and hypoparathyroidism are well-recognized important complications of thyroid surgery and the overall complication rates of thyroidectomy have a varying range for both RLN injury up to $1-14 \%$ and permanent hypoparathyroidism up to $1-11 \%$ [23] and these complications can be prevented with appropriate surgical technique during total thyroidectomy [24,25]. However, using the ligasure sealing system these figures are much more reduced in our data and in previous studies of same interest that compared ligasure versus conventional titanium clips and surgical ties during thyroidectomy and found that Voice Handicap Index scores significantly lower with ligasure compared to conventional surgery [26,27]. The accepted explanation of this reduction rate in nerve and parathyroid injury is that ligasure has the ability to reduce energy spread profile $(<2 \mathrm{~mm})$ when compared with 
unipolar cautery, with a potential decreased risk of injury to adjacent structures [28,29]. Khafagy and Abdelnaby [13] stated that standard vessel ligation, involving use of ties and suture ligatures, although being a highly efficient technique for vessel bleeding control, it is time consuming and can endanger adjacent structures such as the recurrent and superior laryngeal nerves.

The duration and total volume of postoperative drain discharge were significantly reduced in ligasure versus conventional group [30] and the incidence of seroma formation was fewer when ligasure is compared with the conventional suture- ligation technique [31].

The rates of infection after thyroidectomy have significantly decreased with improvements in technology and aseptic technique and the usual presentation is a superficial cellulitis with warmth, erythema, and tenderness surrounding the surgical incision. Other signs of infection, such as fever and leukocytosis, without an overlying cellulitis, may point to a deep space neck infection or abscess [32]. Postoperative wound infection was observed a bit higher following total thyroidectomy than lobectomy due to more tissue trauma [33] and the surgical site infection rate was detected in the conventional suture knot tying technique group and there was no infection sign in the ligasure group in another study [6]. The accepted explanation of this reduction rate is that the conventional suture knot tying technique requires a large number of surgical ties and is time consuming ,decreases healing as well as increases wound infection, requires good exposure, injury to neighboring structures and foreign body reaction [7]

\section{Conclusion}

The use of the Ligasure sealing system in total thyroidectomy is proved safe and effective in reducing the operative time, intraoperative blood loss together with reduction in postoperative fluid drainage. Owing to the ability to reduce energy spread profile, use of Ligasure sealing system is accompanied with better outcome regarding the function of laryngeal nerves and parathyroids.

\section{References}

[1] Harold KL, Pollinger H, Matthews BD, Kercher KW, Sing RF, Heniford BT. Comparison of ultrasonic energy, bipolar thermal energy, and vascular clips for the hemostasis of small-, medium-, and large-sized arteries. Surg Endosc 2003;17:122830 .

[2] Lee WJ, Chen TC, Lai IR, Wang W, Huang MT. Randomized clinical trial of Ligasure versus conventional surgery for extended gastric cancer resection. Br J Surg 2003;90:1493-6

[3] Dubuc-Lissoir J. Use of a new energy-based vessel ligation device during laparoscopic gynecologic oncologic surgery. Surg Endosc 2003;17:466-8.

[4] Person B1, Vivas DA, Ruiz D, Talcott M, Coad JE, Wexner
SD. Comparison of four energy-based vascular sealing and cutting instruments: A porcine model. Surg Endosc. 2008 Feb;22(2):534-8.

[5] Rifaat M, Saber A, Hokkam EN. Total Versus Subtotal Thyroidectomy for Benign Multinodular Goiter: Outcome and Complications. J Curr Surg. 2014;4(2):40-45

[6] Cakabay B, Sevinç MM, Gömceli I, Yenidogan E, Ulkü A, Koç S. LigaSure versus Clamp-and-Tie in Thyroidectomy: a Single-Center Experience. Adv Ther. 2009 ;26(11):1035-41

[7] Challa. S, Sushama Surapaneni. Sutureless thyroidectomy vasucular control using bipolar electrothermal cautery. J Evolution Medical Dental Sciences. 2012;1(6):1083-1086

[8] Musholt TJ. [Total thyroidectomy for multinodular goiter]. Chirurg. 2010; 81(7):603-606, 608-611.

[9] Ruggiero R, Docimo L, Tolone S, De Palma M, Musella M, Pezzolla A, Gubitosi A, Parmeggiani D, Pirozzi R, Gili S, Parisi S, D'Alessandro A,Docimo G. Effectiveness of an advanced hemostatic pad combined with harmonic scalpel in thyroid surgery. A prospective study. Int J Surg. 2015 Dec 17. pii: S1743-9191(15)01429-6.

[10] Schiphorst AH, Twigt BA, Elias SG, van Dalen T. Randomized clinical trial of LigaSure versus conventional suture ligation in thyroid surgery. Head Neck Oncol. 2012 Jan 18;4:2. doi: 10.1186/1758-3284-4-2.

[11] Saint Marc O1, Cogliandolo A, Piquard A, Famà F, Pidoto RR LigaSure vs Clamp-and-Tie Technique to Achieve Hemostasis in Total Thyroidectomy for Benign Multinodular GoiterA Prospective Randomized Study. Arch Surg. 2007 Feb;142(2):150-6.

[12] Yao HS, Wang Q, Wang WJ, Ruan CP. Prospective clinical trials of thyroidectomy with LigaSure vs conventional vessel ligation: a systematic review and meta-analysis. Arch Surg. 2009 Dec;144(12):1167-74.

[13] Khafagy AH, ,Abdelnaby I . Total thyroidectomy: Ligasure versus Clamp \& Knot technique for intraoperative hemostasis. Egyptian Journal of Ear, Nose, Throat and Allied Sciences. 2013, 14 (2): 59-65

[14] Sukprasert M, Choktanasiri W, Ayudhya NI, Promsonthi P, OPrasertsawat P.Increase accuracy of visual estimation of blood loss from education programme. J Med Assoc Thai. $2006 ; 89$ Suppl 4:S54-9.

[15] Pacagnella RC, Souza JP, Durocher J, et al. A systematic review of the relationship between blood loss and clinical signs. PLoS One. 2013;8(3):e57594

[16] Saber A, Abu-Elela ST, Shaalan KM, Al-Masry AR. Preoperative Prediction of the Difficulty of Laparoscopic Cholecystectomy. J Surg Surgical Res(2015), 1(1): 015-018.

[17] Kpolugbo J, Uhumwangho O, Obasikene G, Alili U.Blood transfusion, antibiotics use, and surgery outcome in thyroid surgery: Experience from a suburban center in Nigeria. Niger J Clin Pract. 2012 Oct-Dec;15(4):458-61

[18] Coiro S, Frattaroli FM, De Lucia F, Manna E, Fabi F, Frattaroli JM, Pappalardo G. A comparison of the outcome using Ligasure ${ }^{\mathrm{TM}}$ small jaw and clamp-and-tie technique inthyroidectomy: a randomized single center study. Langenbecks Arch Surg. 2015 Feb;400(2):247-52. 
[19] Hirunwiwatku P, Tungkavivachagul S. A multicenter, randomized, controlled clinical trial of LigaSure small jaw vessel sealing system versus conventional technique in thyroidectomy. Eur Arch Otorhinolaryngol. $2013 ; 270(7): 2109-14$.

[20] Prokopakis EP, Lachanas VA, Vardouniotis AS, Velegrakis GA The use of the Ligasure vessel sealing system in head and neck surgery: a report on six years of experience and a review of the literature. B-ENT. 2010;6(1):19-25.

[21] Aly Saber, Mohammad Rifaat, Goda Ellabban and Mohammad. A. Gad. Total Thyroidectomy by Loupe Magnification: A Comparative Study. European surgery, 2011, 43, ( 1 ): 49-54

[22] Farahat FY, Hegazy NI and Saber A. Post-thyroidectomy Complications: A Surgical Malpractice .Zag .j Med 2008,

[23] Veyseller B, Aksoy F, Demirhan H, Yıldırım YS, Ertaş B, Açıkalın RM, Kumral TL, Bayraktar GI. Total thyroidectomy in benign thyroid diseases. Kulak Burun Bogaz Ihtis Derg. $2009 ; 19(6): 299-303$.

[24] Hisham, AN; Lukman, MR. Recurrent laryngeal nerve in thyroid surgery: a critical appraisal. ANZ J Surg. 2002;72(12):887-889.

[25] Bron, LP; O'Brien, CJ. Total thyroidectomy for clinically benign disease of the thyroid gland. $\mathrm{Br} \mathrm{J}$ Surg. 2004;91(5):569-574.
[26] Singh P, O’Connell D, Langille M, Dziegielewski P, Allegretto M, Harris J. LigaSure versus conventional hemostasis in thyroid surgery: prospective randomized controlled trial. J Otolaryngol Head Neck Surg, 2010;39 (4): 378-384

[27] Scilletta B, Cavallaro M.P, Ferlito F, Li Destri G, et al.Thyroid surgery without cut and tie: the use of Ligasure for total thyroidectomy. Int Surg,2010; 95 (4) : 293-298

[28] Shen WT, Baumbusch MA, Kebebew E, Duh QY. Use of the electrothermal vessel sealing system versus standard vessel ligation inthyroidectomy. Asian J Surg. 2005 Apr;28(2):86-9.

[29] Slakey DP. Laparoscopic liver resection using a bipolar vessel-sealing device: LigaSure ${ }^{\circledR}$. HPB (Oxford). 2008 Aug 1; 10(4): 253-255.

[30] Fujita T, Doihara H, Ogasawara Y, Shimizu N. Utility of vessel-sealing systems in thyroid surgery. Acta Med Okayama. 2006 Apr;60(2):93-8.

[31] Youssef T, Mahdy T, Farid M, Latif AA. Thyroid surgery: use of the LigaSure Vessel Sealing System versus conventional knot tying. Int J Surg. 2008 Aug;6(4):323-7.

[32] Watkinson JC. Fifteen years' experience in thyroid surgery. Ann R Coll Surg Engl. 2010 Oct. 92(7):541-7.

[33] Dionigi G, Rovera F, Boni L, Dionigi R. Surveillance of surgical site infections after thyroidectomy in a one-day surgery setting. Int J Surg. 2008;6 Suppl 1:S13-5. 